\title{
Effects of a Phone Call Intervention to Promote Adherence to Antiretroviral Therapy and Quality of Life of HIV/AIDS Patients in Baoshan, China: A Randomized Controlled Trial
}

\author{
Dongsheng Huang, ${ }^{1}$ Rassamee Sangthong, ${ }^{2}$ Edward McNeil, ${ }^{2}$ Virasakdi Chongsuvivatwong, \\ Weibin Zheng, ${ }^{1}$ and Xuemei Yang ${ }^{3}$ \\ ${ }^{1}$ Department of Preventing and Controlling HIV/AIDS, Baoshan Prefecture Center for Disease Control and Prevention, \\ Baoshan, Yunnan 678000, China \\ ${ }^{2}$ Epidemiology Unit, Faculty of Medicine, Prince of Songkla University, Hat Yai 90110, Thailand \\ ${ }^{3}$ Baoshan Prefecture AIDS Working Committee Office, Baoshan Prefecture Health Bureau, Baoshan, Yunnan 678000, China
}

Correspondence should be addressed to Dongsheng Huang; hudosh_007@126.com

Received 11 September 2012; Accepted 26 December 2012

Academic Editor: P. K. Nicholas

Copyright (C) 2013 Dongsheng Huang et al. This is an open access article distributed under the Creative Commons Attribution License, which permits unrestricted use, distribution, and reproduction in any medium, provided the original work is properly cited.

\begin{abstract}
Background. Suboptimal adherence to antiretroviral therapy (ART) is still pervasive. The effect of using a mobile phone call intervention to improve patient adherence is currently not known. Objective. This study aims to investigate the effects of a phone call intervention on adherence to ART and quality of life (QOL) of treatment-naive and treatment-experienced patients. Methods. A randomized controlled trial was conducted in the three largest public hospitals. Adherence was measured by self-completed questionnaires. QOL was assessed by the WHOQOL-HIV BREF. Outcomes were assessed at day 15, at 1, 2, and 3 months after start of treatment for treatment-naive patients and at 3 months after study enrollment for treatment-experienced patients. Results. A total of 103 treatment-naive and 93 treatment-experienced HIV/AIDS patients were consecutively recruited. Results show that a phone call intervention could maintain high self-reported adherence among both treatment-naive and treatment-experienced patients. After three months, significant QOL improvements were observed in domains of physical health $(P=0.003)$, level of independence $(P=0.018)$, environment $(P=0.002)$, and spirituality/religion/personal beliefs $(P=0.021)$ among treatment-naive patients. Conclusion. A mobile phone call intervention to patients could maintain high adherence rates although no statistically significant differences were found. A phone call could improve some domains of QOL among treatment-naive patients.
\end{abstract}

\section{Introduction}

Since the beginning of the HIV/AIDS epidemic in 1981, nearly 30 million people have died from AIDS-related causes [1]. Antiretroviral therapy (ART) was initiated in 1996 and has contributed greatly to the reduction in mortality and morbidity among patients with HIV/AIDS [2]. The annual number of people dying from AIDS-related causes worldwide has been steadily decreasing from a peak of 2.2 million in 2005 to an estimated 1.8 million in 2010 [3]. In China, the mortality rate has decreased from 39.3 per 100 person-years in 2002 to 14.2 per 100 person-years in 2009 [4].
While the benefits of ART are well established, poor adherence to the regimens is pervasive [2]. Nonadherence rates range from $30 \%$ to $40 \%$ in the United States of America, Latin America, and Europe [5-8], and in China, it is approximately 20\% [9]. An adherence rate under $95 \%$ accounts for ART failure and results in drug resistance [10]. Thus, it is crucial for patients with HIV/AIDS to consistently comply with the regimen to decrease the risk of disease progression and drug resistance, maintaining CD4 lymphocyte count to prolong their survival and to achieve a better quality of life (QOL) $[11,12]$.

Mobile phone technology using text messages has been shown to be useful to improve adherence rates $[13,14]$. 
However, patients sometimes do not receive the messages, or if they do, ignore them [15]. Previous studies reported that participants prefer interventions that not only act as a reminder but also as a useful source of information on HIV/ AIDS as well as allowing them to enquire about their illness or simply to communicate with their providers $[13,16]$. A phone call intervention [17] has been shown to have promising results in developed countries and has been suggested to be used to improve adherence to ART in resource-limited countries.

China is currently the world's largest mobile phone market [18], and approximately $76 \%$ of the population now own a mobile phone [19]. The present study was therefore carried out to investigate the effect of a phone call intervention to promote adherence to ART and QOL among HIV/AIDS patients in Baoshan, China.

\section{Materials and Methods}

2.1. Study Setting. Baoshan is located in the south western part of Yunnan, close to the Myanmar border, where HIV/ AIDS is highly prevalent $[20,21]$. Baoshan prefecture began to monitor the HIV/AIDS epidemic in 1990. At present, the accumulative number of living cases is totally more than 4,500, and more than 1,500 patients have been under ART (Baoshan CDC internal statistics). This randomized controlled trial (RCT) was conducted in 3 out of 6 county hospitals in Baoshan Prefecture in 2011.

2.2. Study Sample. Based on the national guideline for ART in China [22], patients are indicated for ART when they have (1) a positive confirmatory test for HIV; (2) baseline CD4 count $<350$ cells $/ \mathrm{mm}^{3}$ or baseline WHO clinical staging of III or IV; (3) detailed history and physical examination. These patients were eligible to our study if they were (a) Chinese, (b) at least 18 years of age, (c) owning a mobile phone, (d) not imminently transferring to other hospitals, (e) not a prisoner, pregnant woman, or a hospitalized patient. Recruited patients were classified into two groups, treatment-naive patients and treatment-experienced patients. The latter group have been on treatment for 1 to 3 years. The required sample size was estimated to be at least 75 patients per study arm to detect an improvement of $20 \%$ in adherence rate from $75 \%$ to $95 \%$, with $80 \%$ power, $95 \%$ confidence, and allowing for a $20 \%$ loss to followup.

Eligible patients were consecutively asked to participate in the study. Details of the study were given to patients who agreed to participate in the study, and verbal informed consent was obtained. Treatment-naive and treatment-experienced patients were allocated to either the intervention or control groups by the permuted block of two and four randomization method. The study arm assignment was concealed in an opaque-sealed envelope. If the phone call intervention was allocated, the patient then received information regarding the intervention for 3-5 minutes by a well-trained registered nurse or health personnel.
2.3. Procedures. Two registered nurses or health personnel in each county hospital who had worked at the HIV/AIDS clinic were trained for 2 hours on usual care service including provision of ART information and instructions for taking medicine, general health care and self-management of symptoms related to HIV/AIDS and treatment, and relevant social support. Moreover, the nurse or health personnel who was designated to give the phone call intervention received counseling on stress-related problems, exploring patients' demands and expectations, and how to conduct a telephone appointment and interview, particularly regarding the privacy of the phone call and confidentiality of information.

On the first visit, patients were assessed on their baseline characteristics, attitudes, knowledge, and readiness for treatment by an interview. Relevant clinical information including CD4 count was obtained from the patient's medical record. QOL was examined by the WHOQOL-HIV BREF [23] to obtain six domains of QOL, namely, physical wellbeing, psychological status, level of independence, social relationships, environment and spirituality/religion/personal beliefs.

2.4. Intervention. All patients received usual care services including education on HIV/AIDS and treatment. Questions and health problems could be discussed with the doctor at the clinic. In addition to the usual care, patients in the intervention group were given a hospital phone number and a mobile phone number. The patient's mobile phone number(s) was also recorded. A test call was made, and the date and time for the telephone calls were designated to each patient. A reminder phone call was planned to be made every two weeks except for when a patient arrived for their scheduled follow-up visit. At the start of the call, the patient's name would be identified before any conversation begun. The conversation would be made in a friendly and private manner. A semistructured dialogue eliciting the reasons and difficulties in making a hospital visit, symptoms of treatment, treatment adherence, and difficulty in taking medication was used. Any questions and concerns about medication, health, and related issues were welcome for patients to ask. Each phone would take about 3 minutes. All phone calls and relevant conversation would be noted. If a patient did not answer the phone or another person answered the phone, or it was not convenient for a patient to talk, up to 4 calls on the same day, the call would be attempted later. A successful call referred to a patient was reached and conversation was made.

2.5. Followup. Based on the national guidelines for HIV/ AIDS treatment [22], HIV/AIDS patients were appointed for followup at 15 days, at 1, 2, and 3 months, and then every three months after start of treatment. In this study, patients were followed up for 3 months as designated in the routine followup. Treatment adherence, symptoms related to HIV/AIDS, reasons for not taking medication, if any, QOL, and clinical information were obtained at every followup visit. CD4 count was obtained at baseline and at the 3month follow-up visit only. Clinical information including 


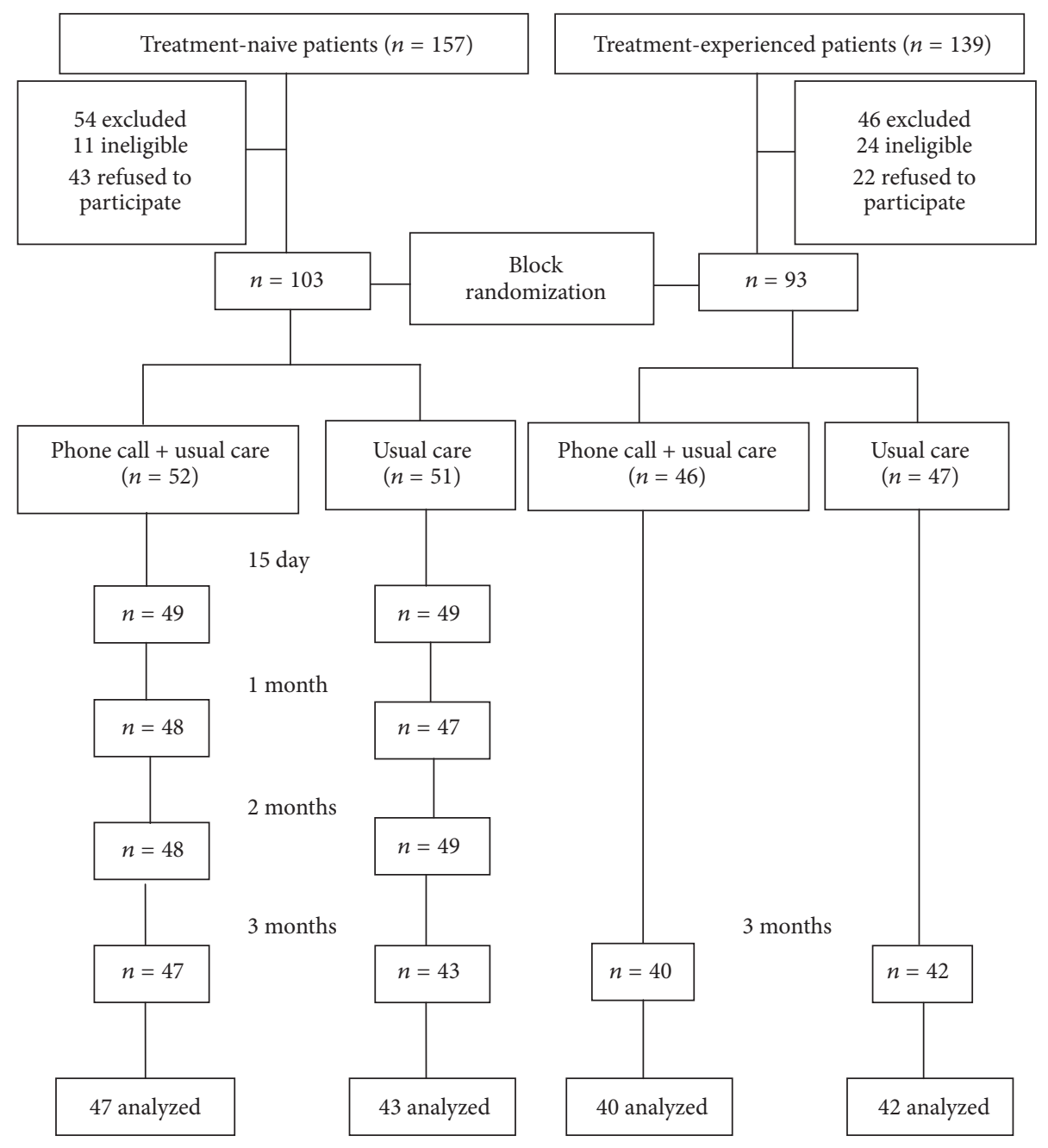

FIGURE 1: Flow chart of study participants.

treatment details such as WHO clinical stage and weight was obtained from the medical records.

2.6. Ethical Consideration. All participants were given details of the study, and verbal informed consent was obtained. Privacy and confidentiality were ensured. Data were kept in a locked drawer and were accessible for only responsible registered nurses or health personnel. The study was approved by the Ethics Committee, Faculty of Medicine, Prince of Songkla University, Thailand and Baoshan Prefecture Health Bureau, China. The study was registered to http://clinicaltrials.gov/, NCT01395771.

2.7. Statistical Analysis. Descriptive statistics were used to compare baseline characteristics between intervention and control groups. Chi-square test or Fisher's exact test and Student's $t$-test were used to compare categorical variables and continuous variables between the two groups. Adherence rate in this study was computed by the percent of the prescribed drug 1 - proportion pills missed $\times 100 \%$ [17]. McNemar's test was used to assess the change in proportion of WHO clinical staging of HIV/AIDS from pre- to postintervention. All data analysis was based on intention-to-treat. Data entry was entered in EpiData version 3.1 [24] and analysed by R version 2.14.0 [25].

\section{Results}

3.1. Flow of Participants. Figure 1 shows that among the 157 treatment-naive patients, 54 were excluded (11 ineligible, 43 refused to participate). Thus, 103 treatment-naive patients were recruited. Among 139 treatment-experienced patients, 46 were excluded ( 24 ineligible, 22 refused). Thus, 93 patients were recruited. The primary reasons for refusal to participate in the study were not having time and having transportation difficulties. After randomization, 52 and 51 treatment-naive, and 46 and 47 treatment-experienced patients were allocated to the intervention and control groups, respectively. The overall follow-up rates at day 15 and months 1, 2, and 3 for treatment-naive patients were $95.1 \%, 92.2 \%, 94.2 \%$, and $87.3 \%$, respectively, while the follow-up rate at 3 months among treatment-experienced patients was $88.2 \%$. 
3.2. Description of Participants. Table 1 shows the comparison of baseline characteristics of participants between the intervention and control groups. Males and females were equally distributed among the two groups and most were aged between 20 and 40 years. Most were Han ethnicity, married or cohabiting, had at least a primary school education, were farmers, and resided in rural areas. The average annual income was below 10,000 Chinese yuan (CNY) (1,577 USD); however, one-third of treatment-naive patients in the control group had an annual income above 10,000 CNY.

Approximately $90 \%$ of all participants had a history of heterosexual contact, while only a few had a history of injecting drug use as a possible route of HIV infection. The average baseline CD4 count ranged from 200 to 350 cells $/ \mathrm{mm}^{3}$; however, approximately one-third of treatmentexperienced patients had a CD 4 count above 350 cells $/ \mathrm{mm}^{3}$. Most patients were WHO clinical stage $\mathrm{I}$, and most patients received the standard regimen, $\mathrm{AZT}+3 \mathrm{TC}+\mathrm{NVP} / \mathrm{EFV}$, for treatment.

3.3. Mobile Phone Calls. Table 2 shows details of the biweekly phone calls made over the 12 -week study period. A total of 231 and 564 phone calls were made for patients in the treatment-naive and treatment-experienced groups, respectively. The overall success rate for treatment-naive patients was $81.7 \%$. The success rate was above $60 \%$ among treatment-experienced patients and was consistent across all call schedules. The average duration of phone calls was $2.9 \pm$ 1.9 minutes and $2.4 \pm 2.0$ minutes in the treatment-naive and treatment-experienced groups, respectively. Conversations conducted over the phone were mostly related to clinical symptoms that patients had experienced recently and sideeffects of their treatment.

3.4. Follow-Up Rate, Treatment Adherence, and Clinical Outcomes. Table 3 compares the follow-up rates, self-reported adherence to treatment, CD4 count, and weight change between the two groups at each visit. The rates tended to be lower among treatment-naive patients, although no significant differences were observed. Among treatment-experienced patients, the 3-month follow-up rate was slightly higher in the intervention group, although, again, no significant difference was observed. The adherence rate among treatment-naive patients in the intervention group was consistently above $98 \%$, whereas it fluctuated slightly in the control group. There were no statistically significant differences in adherence rate, mean CD4 count, weight change, WHO clinical staging, and opportunistic infections between the intervention and control groups in both treatment-naive and treatmentexperienced patients.

3.5. Quality of Life. Table 4 compares the mean WHO-QOL scores in 6 domains and change from baseline to month 3 between the two groups. In all QOL domains, the scores gradually improved over 3 months in both treatment-naive and treatment-experienced patients. Among treatment-naive patients, the mean QOL scores at baseline among the intervention and the control groups were similar. However, the scores after 3 months were significantly higher among patients who received the phone call intervention in domains of physical well-being, level of independence, environment, and spiritual/religious/personal beliefs. No significant differences in change in QOL scores were observed among the treatment-experienced patients.

\section{Discussion}

Results of this RCT show that although a 3-minute mobile phone call intervention had no significant effect on the follow-up rate, adherence to treatment, and clinical outcomes, it could help maintain patient follow-up visits and treatment adherence. The adherence rates in the control group tended to decrease over time. After three months of intervention, significant improvements were observed in QOL domains for physical well-being, level of independence, environment, and spiritual/religion/personal beliefs among treatment-naive patients.

Many interventions have been trialed to promote and maintain adherence rates among patients with HIV/AIDS. Counseling and educational programs have shown to offer no or only minimal improvements to adherence rates [26, 27], while directly observed therapy (DOT) seems to offer no benefit over self-administered treatment [28]. Moreover, DOT is labor intensive, expensive, and can be perceived as intrusive [29]. Monetary incentives have been shown to offer positive reinforcement, but adherence rates are not sustained and return to baseline levels after discontinuation of the intervention [30].

Subsequently, a variety of electronic devices, such as pagers [31], disease management assistance system (DMAS) [32], electronic pill-cap [33], and alarms, have been used to regularly remind patients to take their medication [34]. A recent systematic review [35] confirmed that these devices may result in improved adherence to ART. However, these devices have drawbacks, including inconvenience, high cost, and patient dissatisfaction due to privacy concerns [36, 37]. Moreover, the devices solely serve as a reminder and do not cope with potential adherence barriers, including management of side effects, provision of social support, and allowing the patient to discuss their health problems.

A previous randomized trial in the USA [38] on a scripted serial landline telephone call among treatment-naive HIV/ AIDS patients over 96 weeks showed higher self-reported adherence rates in the telephone group but no statistically significant improvements in virologic outcomes. A subsequent randomized trial in the USA [17] assessing the effect of an 8-minute landline telephone call among treatment-naive patients showed a significantly higher adherence rate at week 64 in the telephone group as well as being able to maintain high adherence rates over time.

Recently, mobile technology for health (mHealth), such as mobile phone use, is a new promising innovative option in health care $[39,40]$. It can surmount barriers such as stigma, loss of privacy, and transportation limitations associated with traditional interventions [13]. The feasibility of mobile phone use in health care among patients with HIV/AIDS has 
TABLE 1: Baseline characteristics of study participants in intervention and control groups.

\begin{tabular}{|c|c|c|c|c|}
\hline \multirow{2}{*}{ Participant characteristic } & \multicolumn{2}{|c|}{ Treatment-naive } & \multicolumn{2}{|c|}{ Treatment-experienced } \\
\hline & Intervention $(n=52)$ & Control $(n=51)$ & Intervention $(n=46)$ & Control $(n=47)$ \\
\hline \multicolumn{5}{|l|}{ Sex (\%) } \\
\hline Male & $24(46.2)$ & $27(52.9)$ & $22(47.8)$ & $21(44.7)$ \\
\hline Female & $28(53.8)$ & $24(47.1)$ & $24(52.2)$ & $26(55.3)$ \\
\hline \multicolumn{5}{|l|}{ Age group (years) } \\
\hline $20-40$ & $38(73.1)$ & $39(76.5)$ & $32(69.6)$ & $34(72.3)$ \\
\hline$>40-60$ & $14(26.9)$ & $10(19.6)$ & $13(28.3)$ & $13(27.6)$ \\
\hline$>60$ & $0(0.0)$ & $2(3.9)$ & $1(2.2)$ & $0(0.0)$ \\
\hline \multicolumn{5}{|l|}{ Ethnicity (\%) } \\
\hline Han & $41(78.8)$ & $49(96.1)$ & $41(89.1)$ & $40(85.1)$ \\
\hline Other & $11(21.2)$ & $2(3.9)$ & $5(10.9)$ & $7(14.9)$ \\
\hline \multicolumn{5}{|l|}{ Marital status (\%) } \\
\hline Single & $3(5.8)$ & $2(3.9)$ & $3(6.5)$ & $2(4.3)$ \\
\hline Married/cohabiting & $44(84.6)$ & $46(90.2)$ & $41(89.1)$ & $39(83.0)$ \\
\hline Divorced/widowed & $5(9.6)$ & $3(5.9)$ & $2(4.3)$ & $6(12.8)$ \\
\hline \multicolumn{5}{|l|}{ Education level (\%) } \\
\hline None & $4(7.7)$ & $3(5.9)$ & $3(6.5)$ & $3(6.4)$ \\
\hline Primary school & $21(40.4)$ & $24(47.1)$ & $14(30.4)$ & $18(38.3)$ \\
\hline Junior high school & $24(46.2)$ & $19(37.3)$ & $22(47.8)$ & $20(42.6)$ \\
\hline High school or above & $3(5.8)$ & $5(9.8)$ & $7(15.2)$ & $6(12.8)$ \\
\hline \multicolumn{5}{|l|}{ Occupation (\%) } \\
\hline Agriculture & $44(84.6)$ & $41(80.4)$ & $37(80.4)$ & $37(78.7)$ \\
\hline Business & $6(11.5)$ & $7(13.7)$ & $3(6.5)$ & $2(4.3)$ \\
\hline Other & $2(3.8)$ & $3(5.9)$ & $6(13.0)$ & $8(17.0)$ \\
\hline \multicolumn{5}{|l|}{ Residential area (\%) } \\
\hline Rural & $47(90.4)$ & $48(92.3)$ & $39(84.8)$ & $43(91.5)$ \\
\hline Urban & $5(9.6)$ & $4(7.7)$ & $7(15.2)$ & $4(8.5)$ \\
\hline \multicolumn{5}{|l|}{ Annual income $(\mathrm{CNY})^{\mathrm{a}}$} \\
\hline$<2000$ & $22(42.3)$ & $18(35.3)$ & $14(30.4)$ & $9(19.1)$ \\
\hline $2000-10000$ & $21(40.4)$ & $15(29.4)$ & $24(52.2)$ & $31(66)$ \\
\hline$>10000$ & $9(17.3)$ & $18(35.3)$ & $8(17.4)$ & $7(14.9)$ \\
\hline \multicolumn{5}{|l|}{ Transmission route (\%) } \\
\hline Heterosexual & $46(88.5)$ & $42(82.4)$ & $43(93.5)$ & $44(93.6)$ \\
\hline Injecting drug use & $6(11.5)$ & $8(15.7)$ & $2(4.3)$ & $5(10.6)$ \\
\hline Other & $4(7.7)$ & $8(15.7)$ & $1(2.2)$ & $1(2.1)$ \\
\hline \multicolumn{5}{|l|}{ CD4 count (cells $\left./ \mathrm{mm}^{3}\right)$} \\
\hline$\leq 100$ & $12(23.1)$ & $9(17.6)$ & $2(4.4)$ & $1(2.2)$ \\
\hline$>100-200$ & $13(25.0)$ & $10(19.6)$ & $10(22.2)$ & $8(17.8)$ \\
\hline$>200-350$ & $27(51.9)$ & $32(62.7)$ & $18(40)$ & $21(46.7)$ \\
\hline$>350$ & - & - & $15(33.3)$ & $15(33.3)$ \\
\hline \multicolumn{5}{|l|}{ WHO clinical staging (\%) } \\
\hline I & $30(57.7)$ & $36(70.6)$ & $26(56.5)$ & $22(46.8)$ \\
\hline II & $10(19.2)$ & $6(11.8)$ & $6(13.0)$ & $12(25.5)$ \\
\hline$\geq$ III or IV & $12(23.1)$ & $9(17.6)$ & $14(30.4)$ & $13(27.7)$ \\
\hline \multicolumn{5}{|l|}{ ART regimen $(\%)$} \\
\hline $\mathrm{AZT}+3 \mathrm{TC}+\mathrm{EFV}^{\mathrm{b}}$ & $19(36.5)$ & $15(29.4)$ & $9(19.6)$ & $11(23.4)$ \\
\hline $\mathrm{AZT}+3 \mathrm{TC}+\mathrm{NVP}^{\mathrm{c}}$ & $28(53.8)$ & $31(60.8)$ & $26(56.5)$ & $23(48.9)$ \\
\hline Other & $5(9.6)$ & $5(9.8)$ & $11(23.9)$ & $13(27.7)$ \\
\hline
\end{tabular}

${ }^{\mathrm{a}} 1 \mathrm{USD}=6.36 \mathrm{CNY} ;{ }^{\mathrm{b}, \mathrm{c}}$ AZT: Zidovudine; 3TC: Lamivudine; NVP: Nevirapine; EFV: Efavirenz; ART: antiretroviral therapy. 
TABLE 2: Details of the biweekly phone calls made over the 12-week study period.

\begin{tabular}{|c|c|c|c|c|c|c|}
\hline \multirow[b]{2}{*}{$\begin{array}{l}\text { Phone call } \\
\text { appointment }\end{array}$} & \multicolumn{3}{|c|}{ Treatment-naive patients } & \multicolumn{3}{|c|}{ Treatment-experienced patients } \\
\hline & $\begin{array}{l}\text { No. of patients } \\
\text { requiring a phone } \\
\text { call } n=52\end{array}$ & $\begin{array}{l}\text { No. of successful calls } \\
n(\%)\end{array}$ & $\begin{array}{l}\text { Call time }(\mathrm{min}) \\
(\text { mean } \pm \mathrm{SD})\end{array}$ & $\begin{array}{l}\text { No. of patients } \\
\text { requiring a phone } \\
\text { call } n=46\end{array}$ & $\begin{array}{l}\text { No. of successful calls } \\
n(\%)\end{array}$ & $\begin{array}{l}\text { Call time }(\mathrm{min}) \\
(\text { mean } \pm \mathrm{SD})\end{array}$ \\
\hline Day 15 & 3 & $2(66.0)$ & $4.7 \pm 1.2$ & 46 & $32(69.6)$ & $2.5 \pm 2.2$ \\
\hline Month 1 & 4 & $3(75.0)$ & $6.0 \pm 0.0$ & 46 & $30(65.2)$ & $2.3 \pm 2.2$ \\
\hline Month 1.5 & 51 & $46(90.2)$ & $3.0 \pm 1.8$ & 46 & $28(60.9)$ & $2.2 \pm 1.2$ \\
\hline Month 2 & 6 & $2(33.3)$ & $1.0 \pm 1.4$ & 46 & $29(63.4)$ & $2.4 \pm 2.1$ \\
\hline Month 2.5 & 51 & $44(86.2)$ & $3.0 \pm 1.8$ & 46 & $29(63.4)$ & $3.1 \pm 1.9$ \\
\hline Month 3 & 5 & $1(20.0)$ & $3.0 \pm 0.0$ & 6 & $6(100.0)$ & $0.6 \pm 1.3$ \\
\hline Overall & 120 & $98(81.7)$ & $2.9 \pm 1.9$ & 236 & $154(65.3)$ & $2.4 \pm 2.0$ \\
\hline
\end{tabular}

TABLE 3: Follow-up rate, self-reported adherence to treatment, CD4, and weight change between intervention and control groups over time.

\begin{tabular}{|c|c|c|c|c|c|c|c|c|c|c|}
\hline & \multicolumn{4}{|c|}{ Treatment-naive patients } & \multicolumn{6}{|c|}{ Treatment-experienced patients } \\
\hline & \multirow[b]{2}{*}{$n$} & \multicolumn{2}{|c|}{ Group } & \multirow[b]{2}{*}{ Control } & \multirow{2}{*}{$P$ value } & \multirow[b]{2}{*}{$n$} & \multicolumn{2}{|c|}{ Group } & \multirow[b]{2}{*}{ Control } & \multirow{2}{*}{$P$ value } \\
\hline & & Intervention & $n$ & & & & Intervention & $n$ & & \\
\hline \multicolumn{11}{|c|}{ Follow-up rate $(\%)$} \\
\hline Visit 1 & 49 & 94.2 & 48 & 94.1 & 0.17 & 42 & 91.3 & 46 & 97.9 & 0.82 \\
\hline Visit 2 & 48 & 92.3 & 47 & 92.2 & 0.20 & & - & - & & \\
\hline Visit 3 & 48 & 92.3 & 49 & 94.2 & 0.10 & & - & - & & \\
\hline Visit 4 & 47 & 90.3 & 43 & 84.3 & 0.08 & 44 & 95.7 & 44 & 93.6 & 0.66 \\
\hline \multicolumn{11}{|c|}{ Self-reported adherence, mean (SD) } \\
\hline Baseline & 52 & - & 51 & - & & 46 & $99.2(2.3)$ & 47 & $99.1(2.5)$ & 0.83 \\
\hline Day 15 & 40 & $98.9(3.9)$ & 36 & $97.3(11.2)$ & 0.98 & & - & & - & \\
\hline Month 1 & 29 & $98.7(5.3)$ & 19 & $94.7(22.5)$ & 0.19 & & - & & - & \\
\hline Month 2 & 32 & $99.8(0.8)$ & 33 & $97.0(17.2)$ & 0.98 & & - & & - & \\
\hline Month 3 & 30 & $99.7(1.6)$ & 31 & $96.5(17.8)$ & 0.09 & 40 & $99.6(1.0)$ & 42 & $99.5(2.0)$ & 0.37 \\
\hline \multicolumn{11}{|c|}{$\mathrm{CD} 4\left(\right.$ cell count $\left./ \mathrm{mm}^{3}\right)$ mean $(\mathrm{SD})$} \\
\hline Baseline & 49 & $191(99.6)$ & 47 & $216(98.2)$ & 0.23 & 39 & $286(129.7)$ & 40 & $348(195.6)$ & 0.10 \\
\hline Month 3 & 40 & $308(124.3)$ & 38 & 298 (121.9) & 0.82 & 36 & $324(125.0)$ & 27 & $356(197.5)$ & 0.47 \\
\hline Pre- to postchange & 40 & $111(97.3)$ & 38 & $91.9(87.8)$ & 0.35 & 36 & $32.1(79.0)$ & 27 & $12.3(80.3)$ & 0.34 \\
\hline \multicolumn{11}{|c|}{ Weight $(\mathrm{kg})$ mean $(\mathrm{SD})$} \\
\hline Baseline & 49 & $54.1(8.6)$ & 47 & $56.7(9.6)$ & 0.15 & 46 & $57.3(9.1)$ & 47 & $53.4(7.8)$ & 0.02 \\
\hline Month 3 & 46 & $54.2(9.3)$ & 43 & $57.3(9.4)$ & 0.12 & 39 & $57.2(9.4)$ & 40 & $53.3(8.0)$ & 0.05 \\
\hline Pre- to postchange & 46 & $0.9(3.0)$ & 43 & $0.6(2.3)$ & 0.61 & 39 & $0.2(2.1)$ & 40 & $0.04(1.8)$ & 0.77 \\
\hline
\end{tabular}

been demonstrated in both developed and resource-limited countries [13, 14, 41-43]. Mobile phone technology can offer medication reminders via a short message service, voice call, dissemination of information, and communication with health workers. However, some studies $[15,44]$ have reported that a reminder can easily be ignored. Patients prefer to obtain information and be given the opportunity to communicate with health workers.

Our study is one of the first RCTs to assess mobile phone use $[14,41,45]$ on adherence rates among patients with HIV/AIDS. A weekly mobile phone message over 12 months in Kenya [14] was found to improve patient adherence rates. Two other protocols $[41,45]$ are currently in progress, and the results will hopefully offer a better understanding of the use of this technology. In addition to reminding services as provided in other RCTs $[14,41,45]$, our study offered a combination of reminder, information dissemination, and communication with health workers through a biweekly mobile phone call service. Although adherence rates were not significantly better in the intervention group, they were sustained across all follow-up visits among treatment-naive patients. The usefulness of mobile phone intervention may thus be confined to treatment-naive patients. Those patients lack knowledge and experience in ART and self-care and have not yet developed their own coping mechanisms, unlike treatment-experienced patients. The questions most commonly asked by patients related to symptoms experienced, such as poor appetite, fever, fatigue, side-effects and toxicity 
TABLE 4: Comparison of quality of life domains and change (mean, SD) from baseline to month 3 between intervention and control groups.

\begin{tabular}{|c|c|c|c|c|c|c|c|c|c|c|}
\hline \multirow{2}{*}{ Domain } & \multicolumn{4}{|c|}{ Treatment-naive patients } & \multirow{2}{*}{$P$ value } & \multicolumn{4}{|c|}{ Treatment-experienced patients } & \multirow{2}{*}{$P$ value } \\
\hline & $n$ & Intervention & $n$ & Control & & $n$ & Intervention & $n$ & Control & \\
\hline \multicolumn{11}{|c|}{ Physical well-being } \\
\hline Baseline & 52 & $12.6 \pm 3.4$ & 51 & $13.8 \pm 2.6$ & 0.044 & 46 & $14.3 \pm 2.2$ & 47 & $13.9 \pm 2.8$ & 0.478 \\
\hline Month 3 & 30 & $16.5 \pm 4.0$ & 31 & $15.8 \pm 3.3$ & 0.414 & 40 & $16.8 \pm 2.5$ & 42 & $16.3 \pm 2.6$ & 0.319 \\
\hline Change & 30 & $4.3 \pm 3.5$ & 31 & $1.5 \pm 3.7$ & 0.003 & 40 & $2.55 \pm 3.2$ & 42 & $2.38 \pm 3.4$ & 0.817 \\
\hline \multicolumn{11}{|c|}{ Psychological status } \\
\hline Baseline & 52 & $11.7 \pm 2.21$ & 51 & $11.7 \pm 2.2$ & 0.875 & 46 & $12.1 \pm 2.1$ & 47 & $12.1 \pm 2.0$ & 0.886 \\
\hline Month 3 & 30 & $13.3 \pm 2.14$ & 31 & $12.9 \pm 1.9$ & 0.468 & 40 & $13.9 \pm 1.7$ & 42 & $13.0 \pm 2.4$ & 0.055 \\
\hline Change & 30 & $1.6 \pm 2.37$ & 31 & $1.1 \pm 2.8$ & 0.485 & 40 & $1.78 \pm 2.4$ & 42 & $0.95 \pm 2.5$ & 0.126 \\
\hline \multicolumn{11}{|c|}{ Level of independence/work capacity } \\
\hline Baseline & 52 & $12.2 \pm 2.8$ & 51 & $13.2 \pm 2.6$ & 0.083 & 46 & $13.9 \pm 2.7$ & 47 & $13.1 \pm 2.0$ & 0.159 \\
\hline Month 3 & 30 & $13.3 \pm 2.3$ & 31 & $12.9 \pm 1.5$ & 0.465 & 40 & $13.7 \pm 1.7$ & 42 & $13.0 \pm 1.7$ & 0.054 \\
\hline Change & 30 & $1.4 \pm 2.5$ & 31 & $-0.4 \pm 3.2$ & 0.018 & 40 & $-0.2 \pm 2.4$ & 42 & $-0.1 \pm 2.1$ & 0.949 \\
\hline \multicolumn{11}{|c|}{ Social relationships } \\
\hline Baseline & 52 & $13.2 \pm 2.3$ & 51 & $13.5 \pm 2.4$ & 0.477 & 46 & $13.3 \pm 3.1$ & 47 & $13.4 \pm 2.4$ & 0.864 \\
\hline Month 3 & 30 & $15.0 \pm 2.2$ & 31 & $14.4 \pm 2.7$ & 0.353 & 40 & $14.9 \pm 2.2$ & 42 & $14.3 \pm 2.2$ & 0.172 \\
\hline Change & 30 & $1.8 \pm 2.2$ & 31 & $0.7 \pm 3.3$ & 0.114 & 40 & $1.7 \pm 3.3$ & 42 & $0.9 \pm 2.2$ & 0.214 \\
\hline \multicolumn{11}{|c|}{ Environment } \\
\hline Baseline & 52 & $11.7 \pm 2.2$ & 51 & $12.5 \pm 2.4$ & 0.072 & 46 & $12.0 \pm 2.5$ & 47 & $12.0 \pm 2.7$ & 0.983 \\
\hline Month 3 & 30 & $13.6 \pm 2.2$ & 31 & $12.7 \pm 2.0$ & 0.101 & 40 & $14.0 \pm 2.3$ & 42 & $13.1 \pm 2.1$ & 0.073 \\
\hline Change & 30 & $1.8 \pm 2.0$ & 31 & $-0.03 \pm 2.1$ & 0.002 & 40 & $2.0 \pm 2.6$ & 42 & $1.1 \pm 2.8$ & 0.135 \\
\hline \multicolumn{11}{|c|}{ Spiritual/religious/personal beliefs } \\
\hline Baseline & 52 & $11.1 \pm 3.5$ & 51 & $12.4 \pm 3.5$ & 0.066 & 46 & $12.8 \pm 3.7$ & 47 & $12.0 \pm 3.0$ & 0.248 \\
\hline Month 3 & 30 & $15.5 \pm 3.0$ & 31 & $14.6 \pm 3.6$ & 0.297 & 40 & $16.2 \pm 2.9$ & 42 & $15.1 \pm 3.3$ & 0.123 \\
\hline Change & 30 & $4.3 \pm 2.9$ & 31 & $2.4 \pm 3.4$ & 0.021 & 40 & $3.3 \pm 4.5$ & 42 & $3.1 \pm 4.4$ & 0.836 \\
\hline
\end{tabular}

of the treatment, and problems with opportunistic infection. Similarly, a previous pilot study [44] on mobile phone surveys for HIV/AIDS care in southern India reported that most calls were related to ART toxicity, ART initiation, and management of opportunistic infections.

In addition to adherence rate, QOL is an important concern in health care and treatment provision. While many electronic devices have been invented, primarily to improve adherence rates, they showed no improvement in QOL [34, 37]. For example, the DMAS [37] provides a verbal reminder of the medication time but results in deterioration of the patient's QOL which may be due to a violation of the patient's privacy by the reminder, explained by the authors.

QOL has not yet been evaluated in other RCTs where mobile phone use was used as the intervention [41, 45], whereas the mobile phone call in our study supported a better QOL among treatment-naive patients. Similarly, a recent intervention study investigating home visits and a telephone intervention conducted in China [46] reported improvement of adherence rate and QOL for physical, psychological, social, and environmental domains. Stand-alone devices which provide reminders but lack the ability to allow patients to communicate with health personnel may improve adherence rates, but they cannot improve the QOL of patients with HIV/AIDS. Previous studies $[13,16]$ reported that patients prefer interventions which not only act as a reminder but also provide a source of useful information on HIV/AIDS as well as allowing them to communicate with healthcare providers.

Although this study had a strong study design, the sample size was too small to detect differences in adherence rates between the intervention and the control groups. The post hoc power of the study ranged from only $40 \%$ to $60 \%$ across follow-up visits. High self-reported adherence rates in our study were observed in both the intervention and control groups. Although the high adherence to ART in China has also been reported in another study [47], this may also be a result of the Hawthorn effect where patients tend to modify their behaviors or response under close observation and assessment while participating in a study. Due to budget constraints, viral loads were too expensive to be monitored. A larger study with longer follow-up duration assessing adherence to treatment, QOL, and cost-effectiveness should be conducted to tailor the most suitable intervention in this setting.

\section{Conflict of Interests}

The authors declare that they have no financial conflict of interests. 


\section{Acknowledgments}

The authors would like to thank the nurses, health personnel, and all participants who kindly cooperated with the researchers in the study.

\section{References}

[1] UNAIDS, "Unite for universal access: Overview brochure on 2011 High Level Meeting on AIDS," New York, NY, USA, Joint United Nations Programme on HIV/AIDS, 2011.

[2] N. R. Reynolds, "Adherence to antiretroviral therapies: state of the science," Current HIV Research, vol. 2, no. 3, pp. 207-214, 2004.

[3] WHO, UNAIDS, and UNICEF, "Global HIV/AIDS response: epidemic update and health sector progress towards universal access:progress report," The World Health Orgnization, Geneva, Switzerland, 2011.

[4] F. Zhang, Z. Dou, Y. Ma et al., "Effect of earlier initiation of antiretroviral treatment and increased treatment coverage on HIV-related mortality in China: a national observational cohort study," The Lancet Infectious Diseases, vol. 11, no. 7, pp. 516-524, 2011.

[5] K. M. Harvey, D. Carrington, J. Duncan et al., "Evaluation of adherence to highly active antiretroviral therapy in adults in Jamaica," West Indian Medical Journal, vol. 57, no. 3, pp. 293-297, 2008.

[6] J. A. Bartlett, "Addressing the challenges of adherence," Journal of Acquired Immune Deficiency Syndromes, vol. 29, supplement 1, pp. S2-S10, 2002.

[7] S. Duran, M. Saves, B. Spire et al., "Failure to maintain longterm adherence to highly active antiretroviral therapy: the role of lipodystrophy," AIDS, vol. 15, pp. 2441-2444, 2001.

[8] P. T. Nieuwkerk, M. A. G. Sprangers, D. M. Burger et al., "Limited patient adherence to highly active antiretroviral therapy for HIV-1 infection in an observational cohort study," Archives of Internal Medicine, vol. 161, no. 16, pp. 1962-1968, 2001.

[9] X. Wang and Z. Wu, "Factors associated with adherence to antiretroviral therapy among HIV/AIDS patients in rural China," AIDS, vol. 21, supplement 8, pp. S149-S155, 2007.

[10] M. Chesney, "Adherence to HAART regimens," AIDS Patient Care and STDs, vol. 17, no. 4, pp. 169-177, 2003.

[11] E. Wood, R. S. Hogg, B. Yip, P. R. Harrigan, M. V. O’Shaughnessy, and J. S. Montaner, "Effect of medication adherence on survival of HIV-infected adults who start highly active antiretroviral therapy when the CD4+ cell count is 0.200 to $0.350 \times 10(9)$ cells/L," Annals of Internal Medicine, vol. 139, no. 10, pp. 810-816, 2003.

[12] S. B. Mannheimer, J. Matts, E. Telzak et al., "Quality of life in HIV-infected individuals receiving antiretroviral therapy is related to adherence," AIDS Care, vol. 17, no. 1, pp. 10-22, 2005.

[13] A. Shet, K. Arumugam, R. Rodrigues et al., "Designing a mobile phone-based intervention to promote adherence to antiretroviral therapy in South India," AIDS and Behavior, vol. 14, no. 3, pp. 716-720, 2010.

[14] R. T. Lester, P. Ritvo, E. J. Mills et al., "Effects of a mobile phone short message service on antiretroviral treatment adherence in Kenya (WelTel Kenya1): a randomised trial," The Lancet, vol. 376, no. 9755, pp. 1838-1845, 2010.

[15] K. Sidney, J. Antony, R. Rodrigues et al., "Supporting patient adherence to antiretrovirals using mobile phone reminders: patient responses from South India," AIDS Care, vol. 24, no. 5, pp. 612-617, 2012.

[16] W. H. Curioso and A. E. Kurth, "Access, use and perceptions regarding Internet, cell phones and PDAs as a means for health promotion for people living with HIV in Peru," BMC Medical Informatics and Decision Making, vol. 7, article 24, 2007.

[17] N. R. Reynolds, M. A. Testa, M. Su et al., "Telephone support to improve antiretroviral medication adherence: a multisite, randomized controlled trial," Journal of Acquired Immune Deficiency Syndromes, vol. 47, no. 1, pp. 62-68, 2008.

[18] "China to surpass 1 billion mobile connections in May 2012," News related to ITU Telecommunication/ICT Statistics, 26 July 2011, http://www.itu.int/ITU-D/ict/newslog/China.aspx.

[19] "The Progression of Main Indicators in Communications Industry in February, 2012," Ministry of Industry and Information Technology of China, 2012, http://www.miit.gov.cn/ n11293472/index.html.

[20] W. C. W. Wong and W. Yilin, "A qualitative study on HIV risk behaviors and medical needs of sex workers in a China/ Myanmar border town," AIDS Patient Care and STDs, vol. 17, no. 8, pp. 417-422, 2003.

[21] T. M. Caouette, "Small Dreams Beyond Reach: The Lives of Migrant Children and Yout Along the Borders of China, Myanmar and Thailand," A Participatory Action Research Project of Save the Children, UK, 2001, http://www.humantrafficking.org/publications/164.

[22] Ministry of Health of China Expert Panel on AIDS Clinical Practices, The Manul of National Free Antiretroviral Therapy, People's Health Publishing House, Beijing, China, 2nd edition, 2007.

[23] WHO, "WHOQOL-HIV BREF, Geneva, Switzerland," Mental Health: Evidence and Research Department of Mental Health and Substance Dependence, 1999.

[24] "Epidata [computer program]," Version 3. 1. Odense: The Epidata Association, 2008.

[25] "R [A Language and Environment for Statictical Computing]," Version 2. 14. 0. Vienna, Austria, R Development Core Team, 2011.

[26] M. K. Rawlings, M. A. Thompson, C. F. Farthing et al., "Impact of an educational program on efficacy and adherence with a twice-daily lamivudine/zidovudine/abacavir regimen in underrepresented HIV-infected patients," Journal of Acquired Immune Deficiency Syndromes, vol. 34, no. 2, pp. 174-183, 2003.

[27] R. H. Remien, M. J. Stirratt, C. Dolezal et al., "Couple-focused support to improve HIV medication adherence: a randomized controlled trial," AIDS, vol. 19, no. 8, pp. 807-814, 2005.

[28] N. Ford, J. B. Nachega, M. E. Engel, and E. J. Mills, "Directly observed antiretroviral therapy: a systematic review and metaanalysis of randomised clinical trials," The Lancet, vol. 374, no. 9707, pp. 2064-2071, 2009.

[29] C. A. Liechty and D. R. Bangsberg, "Doubts about DOT: antiretroviral therapy for resource-poor countries," AIDS, vol. 17, no. 9, pp. 1383-1387, 2003.

[30] M. O. Rigsby, M. I. Rosen, J. E. Beauvais et al., "Cue-dose training with monetary reinforcement: pilot study of an antiretroviral adherence intervention," Journal of General Internal Medicine, vol. 15, no. 12, pp. 841-847, 2000.

[31] J. M. Simoni, D. Huh, P. A. Frick et al., "Peer support and pager messaging to promote antiretroviral modifying therapy in seattle: a randomized controlled trial," Journal of Acquired Immune Deficiency Syndromes, vol. 52, no. 4, pp. 465-473, 2009. 
[32] A. S. A. Andrade, H. F. McGruder, A. W. Wu et al., "A programmable prompting device improves adherence to highly active antiretroviral therapy in HIV-infected subjects with memory impairment," Clinical Infectious Diseases, vol. 41, no. 6, pp. 875-882, 2005.

[33] S. A. Safren, E. S. Hendriksen, N. Desousa, S. L. Boswell, and K. H. Mayer, "Use of an on-line pager system to increase adherence to antiretroviral medications," AIDS Care, vol. 15, no. 6, pp. 787-793, 2003.

[34] S. B. Mannheimer, E. Morse, J. P. Matts et al., "Sustained benefit from a long-term antiretroviral adherence intervention: results of a large randomized clinical trial," Journal of Acquired Immune Deficiency Syndromes, vol. 43, supplement 1, pp. S41-S47, 2006.

[35] P. Saberi and M. O. Johnson, “Technology-based self-care methods of improving antiretroviral adherence: a systematic review," PLoS One, vol. 6, Article ID e27533, 2011.

[36] D. Matsui, C. Hermann, J. Klein, M. Berkovitch, N. Olivieri, and G. Koren, "Critical comparison of novel and existing methods of compliance assessment during a clinical trial of an oral iron chelator," Journal of Clinical Pharmacology, vol. 34, no. 9, pp. 944-949, 1994.

[37] A. W. Wu, C. F. Snyder, I. C. Huang et al., "A randomized trial of the impact of a programmable medication reminder device on quality of life in patients with AIDS," AIDS Patient Care and STDs, vol. 20, no. 11, pp. 773-781, 2006.

[38] A. C. Collier, H. Ribaudo, A. L. Mukherjee, J. Feinberg, M. A. Fischl, and M. Chesney, "A randomized study of serial telephone call support to increase adherence and thereby improve virologic outcome in persons initiating antiretroviral therapy," Journal of Infectious Diseases, vol. 192, no. 8, pp. 1398-1406, 2005.

[39] W. A. Kaplan, "Can the ubiquitous power of mobile phones be used to improve health outcomes in developing countries?" Globalization and Health, vol. 2, article 9, 2006.

[40] R. Lester and S. Karanja, "Mobile phones: exceptional tools for HIV/AIDS, health, and crisis management," The Lancet Infectious Diseases, vol. 8, no. 12, pp. 738-739, 2008.

[41] A. De Costa, A. Shet, N. Kumarasamy et al., "Design of a randomized trial to evaluate the influence of mobile phone reminders on adherence to first line antiretroviral treatment in South India-the HIVIND study protocol," BMC Medical Research Methodology, vol. 10, article 25, 2010.

[42] S. Kunutsor, J. Walley, E. Katabira et al., "Using mobile phones to improve clinic attendance amongst an antiretroviral treatment cohort in rural Uganda: a cross-sectional and prospective study," AIDS and Behavior, vol. 14, no. 6, pp. 1347-1352, 2010.

[43] J. A. Puccio, M. Belzer, J. Olson et al., "The use of cell phone reminder calls for assisting HIV-infected adolescents and young adults to adhere to highly active antiretroviral therapy: a pilot study," AIDS Patient Care and STDs, vol. 20, no. 6, pp. 438-444, 2006.

[44] G. Manoharan, S. Dharmarajan, P. K. Ramalingam, S. Mathew, and J. C. Varghese, "Mobile phone communication and health system strengthening: a pilot study of telephonic warmline consultation in HIV care and support in South India," Journal of the International Association of Physicians in AIDS Care, vol. 11, no. 3, pp. 184-187, 2012.

[45] L. Mbuagbaw, L. Thabane, P. Ongolo-Zogo et al., "The cameroon mobile phone sms (CAMPS) trial: a protocol for a randomized controlled trial of mobile phone text messaging versus usual care for improving adherence to highly active antiretroviral therapy," Trials, vol. 12, article 5, 2011.
[46] H. Wang, J. Zhou, L. Huang, X. Li, K. P. Fennie, and A. B. Williams, "Effects of nurse-delivered home visits combined with telephone calls on medication adherence and quality of life in HIV-infected heroin users in Hunan of China," Journal of Clinical Nursing, vol. 19, no. 3-4, pp. 380-388, 2010.

[47] J. M. Simoni, W. T. Chen, D. Huh et al., "A preliminary randomized controlled trial of a nurse-delivered medication adherence intervention among HIV-positive outpatients initiating antiretroviral therapy in Beijing, China," AIDS and Behavior, vol. 15, pp. 919-929, 2011. 


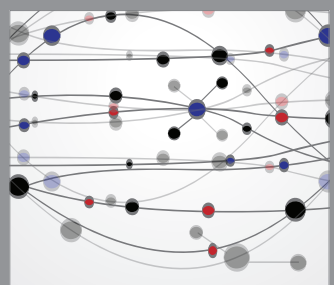

The Scientific World Journal
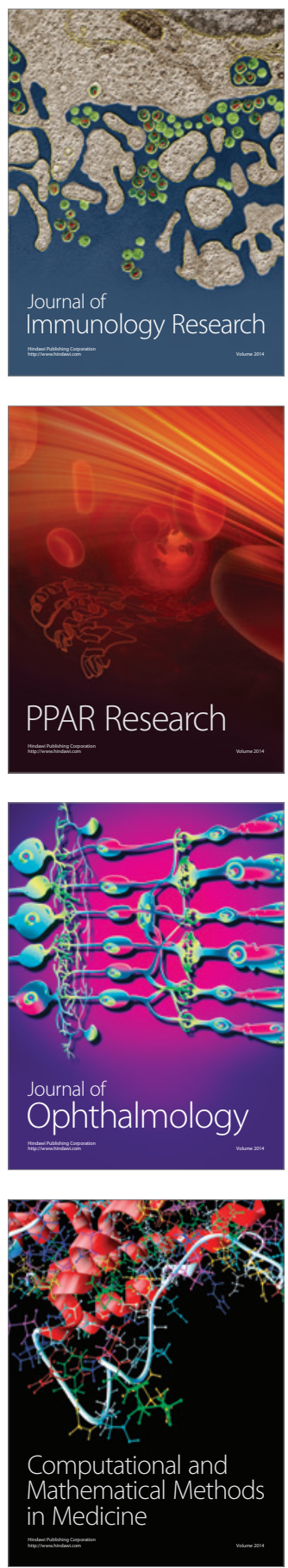

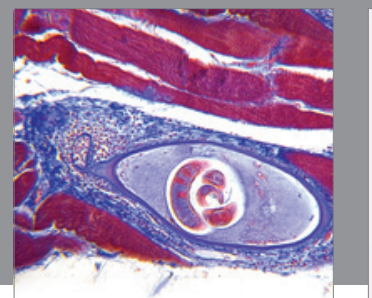

Gastroenterology

Research and Practice
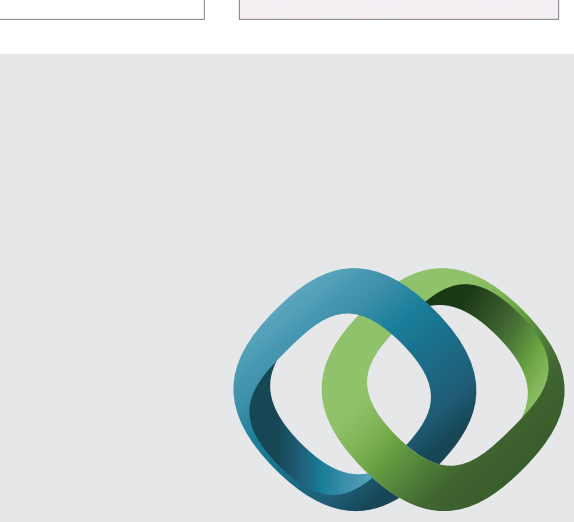

\section{Hindawi}

Submit your manuscripts at

http://www.hindawi.com
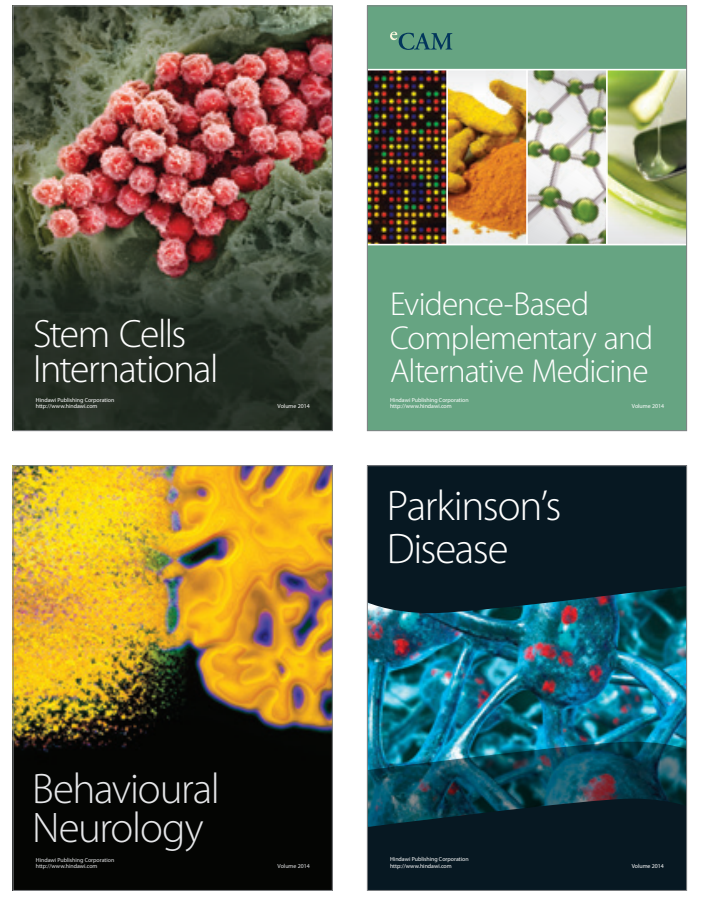
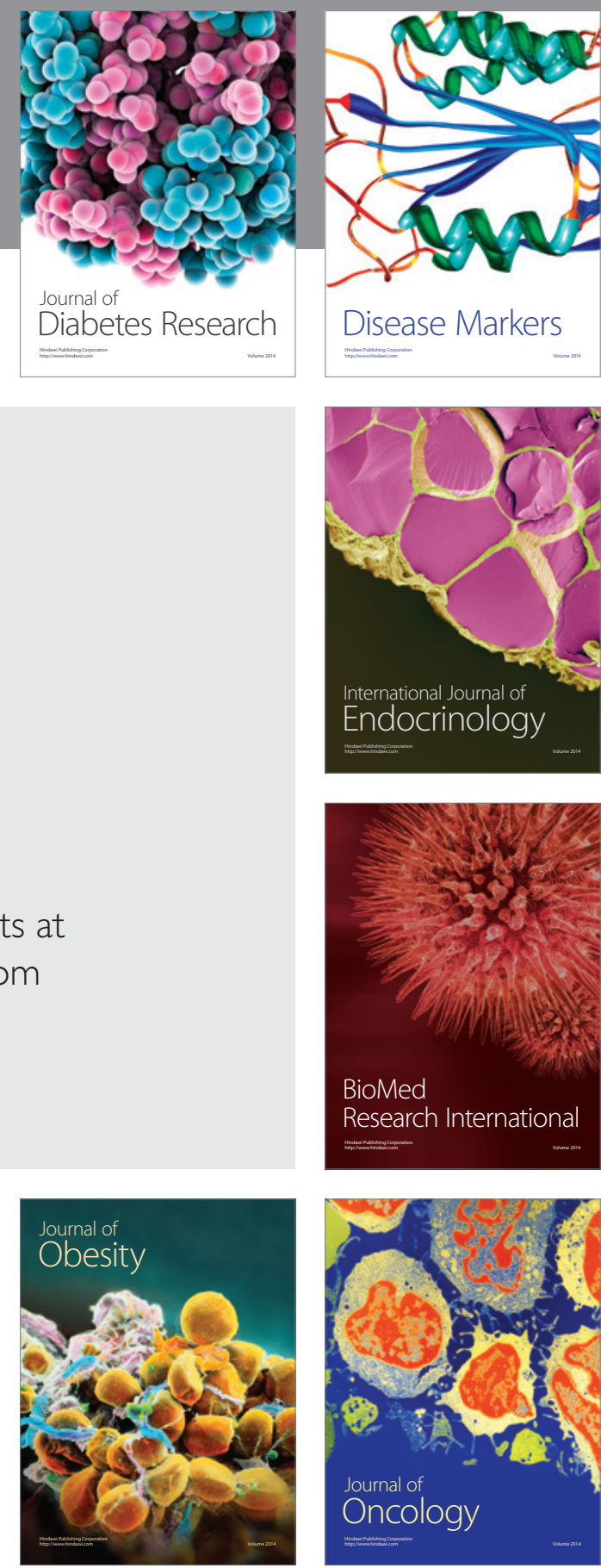

Disease Markers
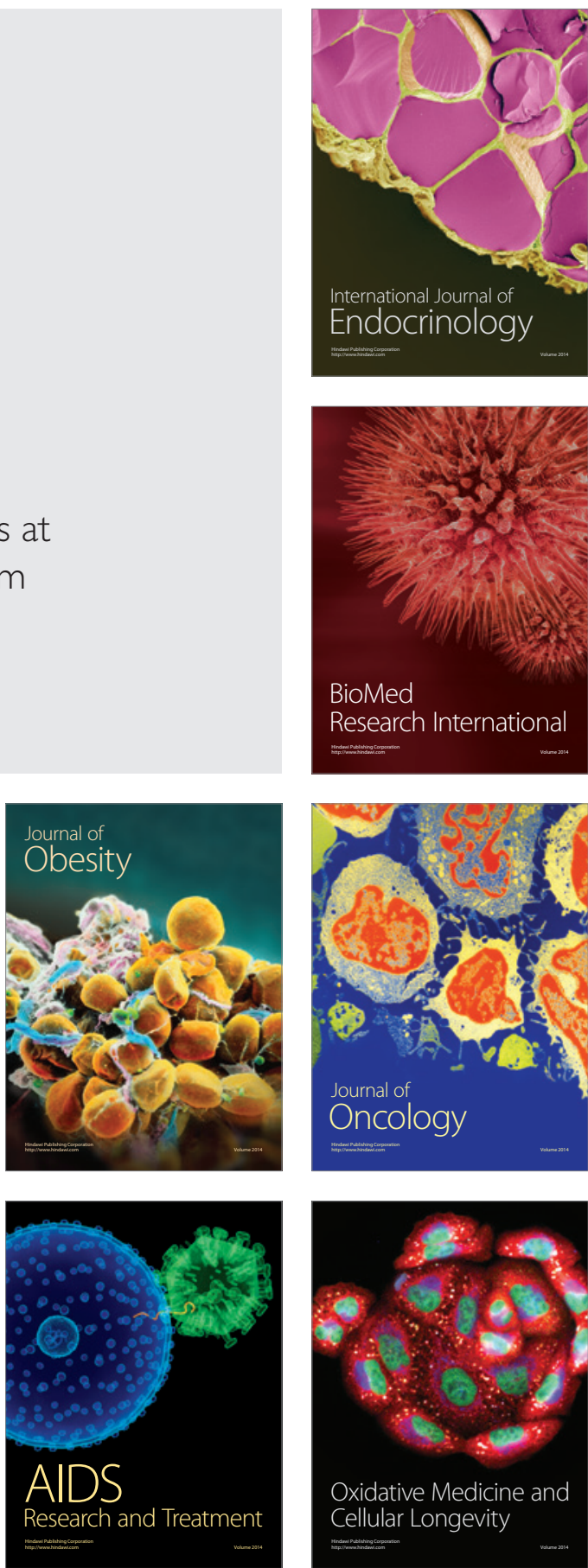